\title{
Genotype-Guided Immunosuppression after Liver Transplantation: Chance for Individualizing Therapy?
}

\section{Daniela Kniepeiss*}

Department of Surgery, Division of Transplantation, Medical University Graz, Austria

"Journal of Liver" is a new, peer-reviewed open access journal from the OMICS Publishing Group and focuses on all aspects of liver, its infections, diagnosis of diseases and treatments. The emphasis will be on publishing quality papers rapidly and freely available to researchers worldwide.

OMICS Publishing Group is an Open Access publication model that enables the dissemination of research articles to the global community. Thus, all articles published under open access can be accessed by anyone. Furthermore, journals of the OMICS group offer special features: "Digital Book" saves paper and will continue to offer benefits as the technology evolves Electronic books. "Audio version" provides exclusive feature of audio listening. "Language translation" is a user friendly and feasible website-translation of published paper to more than 50 languages. The language of interest to read the articles can be chosen which enables worldwide communication with researchers in a variety of languages. "Social networking" offers the possibility to discuss research in various social networking sites.

In the field of transplantation, open access has the advantage of wider dissemination of information and increased efficiency in science, by providing open access to the widest audience. As a researcher, publishing in an open access journal allows anyone with interest to read it - and that translates into increased usage and impact.

Organ transplantation has become an important additional option for patients with organ failure. The immunosuppressive drugs used worldwide after transplantation has a narrow therapeutic index and high inter-individual variations. Overdosing may lead to toxic side-effects, such as infection, malignant diseases or renal dysfunction. Drug levels below the therapeutic range result in sub-optimal immunosuppression and increased risk of acute rejection [1,2]. Especially early after transplantation an efficient and safe achieving of target blood concentrations is important. Intensive drug monitoring is necessary to keep drug levels within therapeutic range. An important goal in transplantation is to tailor immunosuppression to the individual needs of the patient, avoiding both rejection and over-immunosuppression. Opportunistic infections and malignancies remain a significant cause of death after transplantation and are obvious consequences of overimmunosuppression.

In the past years therapeutic drug monitoring has helped physicians to make dosage recommendations based on the individual patient's drug exposure. Currently, monitoring of immunosuppression is conducted mainly on the basis of pharmacokinetic characteristics, which do not necessarily predict clinical outcome in the individual. The question is whether genotyping of the recipient may lead to further individualization of immunosuppressive therapy in transplant patients and whether genotyping might be helpful in determining an appropriate starting dose.

Early studies have shown that pharmacogenetics may provide additional information on how individual genes may affect the response to medications.
Some clinical studies have shown that carriers of the CYP $3 A 5$ * 1 allele require a higher dose of Tacrolimus to achieve the desired drug levels than homozygous carriers of the CYP $3 A 5^{*} 3$ allele [36]. The correlation of the CYP $3 A 5$ genotypes with the dose of Tacrolimus in renal transplant patients was evaluated in a few case series with small sample size and / or short observation time [7-9]. In a few studies the effect of the CYP $3 A 5$ genotypes on the clinical outcome was evaluated. The risk of early acute organ rejection [10], the incidence of delayed graft function [11] and the emergence of calcineurin inhibitor-associated nephrotoxicity [12] were identified. Most pharmacogenomic studies after transplantation investigated renal transplant recipients. Results from patients after liver transplantation are currently very rare and not sufficient to draw conclusions about the clinical relevance.

In a recent European consensus conference the convincing association between CYP $3 A 5$ genotypes and Tacrolimus level concentrations was confirmed [13]. The clinical benefit is currently still unclear and further research in this area has been requested to make clear recommendations possible.

The aim of personalized medicine or individualized treatment is to match the right drug to the right patient. The appropriate treatment for a patient according to his/her genotype could be designed.

Pharmacogenomics could offer the possibility to individualize immunosuppressive therapy based on the patient's genetic profile. However, the clinical applicability of this approach is still to proven. Pharmacogenomics represent still an exciting challenge for the future. Journal of liver could be a discussion forum for this topic and thereby make a contribution to progress in this area.

\section{References}

1. Venkataramanan R, Swaminathan A, Prasad T, Jain A, Zuckerman S, et al. (1995) Clinical pharmacokinetics of tacrolimus. Clin Pharmacokinet 29: 404 430 .

2. Spencer CM, Goa KL, Gillis JC (1997) Tacrolimus. An update of its pharmacology and clinical efficacy in the management of organ transplantation. Drugs 54: 925-975

3. Hesselink DA, van Schaik RH, van der Heiden IP, van der Werf M, Gregoo PJ, et al. (2003) Genetic polymorphisms of the CYP3A4, CYP3A5 and MDR1 genes and pharmacokinetics of the calcineurin inhibitors cyclosporine and tacrolimus. Clin Pharmacol Ther 74: 245-254.

*Corresponding author: Daniela Kniepeiss, MD, Division of Transplantation Department of Surgery, Medical University Graz, Auenbruggerplatz 29, $8036 \mathrm{Graz}$ Austria, Fax: +43 (0) 316385 14446; E-mail: daniela.kniepeiss@meduni-graz.at

Received February 29, 2012; Accepted March 04, 2012; Published March 08, 2012

Citation: Kniepeiss D (2012) Genotype-Guided Immunosuppression afte Liver Transplantation: Chance for Individualizing Therapy?. J Liver 1:e102. doi:10.4172/2167-0889.1000e102

Copyright: (c) 2012 Kniepeiss D. This is an open-access article distributed unde the terms of the Creative Commons Attribution License, which permits unrestricted use, distribution, and reproduction in any medium, provided the original author and source are credited. 
Citation: Kniepeiss D (2012) Genotype-Guided Immunosuppression after Liver Transplantation: Chance for Individualizing Therapy?. J Liver 1:e102. doi:10.4172/2167-0889.1000e102

4. Anglicheau D, Legendre C, Beaune P, Thervet E (2007) Cytochrome P450 3A polymorphisms and immunosuppressive drugs: an update. Pharmacogenomics 8: $835-849$.

5. Thervet E, Anglicheau D, King B, Schlageter MH, Cassinat B, et al. (2003) Impact of cytochrome p450 3A5 genetic polymorphism on tacrolimus doses and concentration-to-dose in renal transplant recipients. Transplantation 76 : 1233-1235.

6. MacPhee IA, Holt DW (2008) A pharmacogenetic strategy for immunosuppression based on the CYP3A5 genotype. Transplantation 85: 163165.

7. Haufroid V, Mourad M, Van Kerckhove V, Wawrzyniak J, De Meyer M, et al. (2004) The effect of CYP3A5 and MDR1 (ABCB1) polymorphisms on cyclosporine and tacrolimus dose requirements and trough blood levels in stable renal transplant patients. Pharmacogenetics 14: 147-154.

8. Katsakiori PF, Papapetrou EP, Sakellaropoulos GC, Goumenos DS, Nikiforidis GC, et al. (2010) Factors affecting the long-term response to tacrolimus in renal transplant patients: pharmacokinetic and pharmacogenetic approach. Int J Med Sci 7: 94-100.
9. Zhang X, Liu ZH, Zheng JM, Chen ZH, Tang Z, et al. (2005) Influence of CYP3A5 and MDR1 polymorphism on tacrolimus concentration in the early stage after renal transplantation. Clin Transplant 19: 638-643.

10. Min SI, Kim SY, Ahn SH, Min SK, Kim SH, et al. (2010) CYP3A5*1 allele: impacts on early acute rejection and graft function in tacrolimus-based renal transplant recipients. Transplantation 90: 1394-1400.

11. Kuypers DR, de Jonge $H$, Naesens M, Vanrenterghem $Y$ (2010) A prospective, open-label, observational clinical cohort study of the association between delayed renal allograft function, tacrolimus exposure and CYP3A5 genotype in adult recipients. Clin Ther 32: 2012-2023.

12. Kuypers DR, Naesens M, de Jonge H, Lerut E, Verbeke K, et al. (2010) Tacrolimus dose requirements and CYP3A5 genotype and the development of Calcineurin inhibitor-associated nephrotoxicity in renal allograft recipients. Ther Drug Monit 32: 394-404.

13. Wallemacq P, Armstrong VW, Brunet M, Haufroid V, Holt DW, et al. (2009) Opportunities to optimize tacrolimus therapy in solid organ transplantation report of the European Consensus Conference. Ther Drug Monit 31: 139-152. 